\title{
Dimensions of the Threat to the Self Posed by Deep Brain Stimulation: Personal Identity, Authenticity, and Autonomy
}

\author{
- Przemysław Zawadzki -
}

\begin{abstract}
Deep Brain Stimulation (DBS) is an invasive therapeutic method involving the implantation of electrodes and the electrical stimulation of specific areas of the brain to modulate their activity. DBS brings therapeutic benefits, but can also have adverse side effects. Recently, neuroethicists have recognized that DBS poses a threat to the very fabric of human existence, namely, to the selves of patients. This article provides a review of the neuroethical literature examining this issue, and identifies the crucial dimensions related to the self which DBS may endanger - personal identity, authenticity, and autonomy. The most influential theories accounting for these dimensions are analyzed herein, and it is argued that most of these theories require further refinement. This paper also demonstrates the interrelation between personal identity, authenticity, and autonomy, and concludes that one can only fully understand the impact of DBS on the self when all of these factors are taken into account. Keywords: self, personal identity, authenticity, autonomy, deep brain stimulation (DBS), neuroethics.
\end{abstract} Published online: 4 June 2021

\section{Therapeutic potential}

Deep Brain Stimulation (DBS) is an invasive therapeutic method involving the implantation of electrodes and the electrical stimulation of specific regions of the brain. ${ }^{1}$ Depending on the disease and treatment strategy, different structures are targeted, for example, the subthalamic nucleus (STN), the globus pallidus internus (GPi), or the nucleus accumbens (NAc). The exact action mechanism of DBS has not yet been confirmed. The proposed models, however, can be divided into four categories. ${ }^{2}$ Models of the first category reduce the effect of DBS to the inhibition of the neuronal activity of the targeted areas for stimulation; the second to the excitation of these areas; models of the third category postulate that its action is due to a combination of these mechanisms; ${ }^{3}$

\footnotetext{
Przemysław Zawadzki Institute of Philosophy Jagiellonian University Grodzka 52 31-044 Krakow

e-mail: przemyslaw.zawadzki@uj.edu.pl

1 Hemm, Wårdell (2010); Herrington, Cheng, Eskandar (2016).

2 Karas, Mikell, Christian et al. (2013); Montgomery, Gale (2008).

3 Vitek (2008).
} 
and the fourth considers DBS to be interrupting pathological oscillations to regain the synchronized, rhythmic activity of the brain waves. ${ }^{4}$

The lack of consensus among researchers about these mechanisms has not prevented the systematic use of this technology for medical purposes. ${ }^{5}$ After the introduction of the first commercial system for clinical use in $1997,{ }^{6}$ DBS proved its therapeutic potential in a number of intractable neurological and psychiatric disorders for which previous treatments (e.g. pharmacotherapy, cognitive behavioral therapy) had not provided satisfactory results, such as Parkinson's disease (PD), ${ }^{7}$ dystonia, ${ }^{8}$ essential tremor, ${ }^{9}$ and obsessive-compulsive disorder (OCD). ${ }^{10}$ This prompted the American Food and Drug Administration (FDA) to approve DBS as a treatment for these ailments. Thus, DBS should be considered a treatment of last resort for patients with no other viable treatment options. ${ }^{11}$ The therapeutic range of DBS is constantly expanding, with experimental studies conducted in the treatment of epilepsy, ${ }^{12}$ Tourette's syndrome, ${ }^{13}$ treatment-resistant depression, ${ }^{14}$ Alzheimer's disease and other forms of dementia, ${ }^{15}$ anorexia, ${ }^{16}{ }^{16}$ obesity, ${ }^{17}$ disorders of consciousness, ${ }^{18}$ chronic pain, ${ }^{19}$ Huntington's disease, ${ }^{20}$ addictions,${ }^{21}$ aggression, ${ }^{22}$ and schizophrenia. ${ }^{23}$ In Poland, DBS is mainly used as a treatment for PD, as well as for dystonia and essential tremor. ${ }^{24}$ Some centers in Poland are also working on the use of DBS for psychiatric disorders: the 10th Military Research Hospital and Polyclinic IPHC in Bydgoszcz, the University Hospital in Wroclaw, and the Wroclaw Medical University have experience in this field. Currently, a multicenter study is planned on the use of DBS in patients with treatment-resistant depression. ${ }^{25}$

Several companies that produce DBS equipment are operating in the market. In 2017, the leading manufacturer, Medtronic Activia, announced that 150,000 patients had already used their systems for DBS therapies, and this number increases annually by

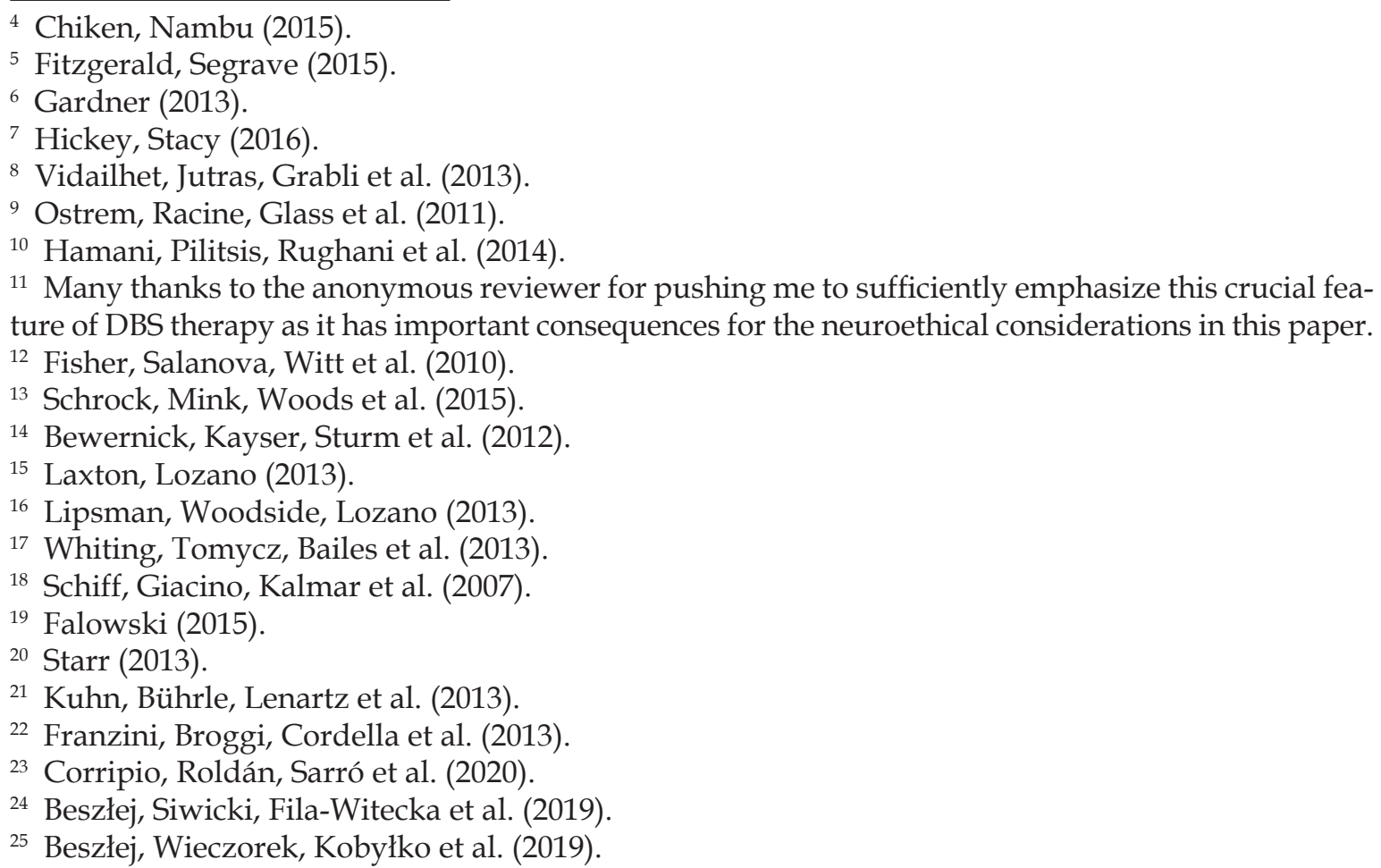


approximately 10,000. Currently, the number of patients considerably exceeds $160,000^{26}$ and is estimated at $175,000 .{ }^{27}$ These numbers show that DBS plays an important role in the lives of many people, and as research progresses on the disorders that are currently under study, this impact will include further groups of patients. ${ }^{28}$

\section{DBS technologies}

DBS systems consist of one or more electrodes inserted into the nervous tissue of the deep brain, connected via a subcutaneous extension wire to a stimulator ("pacemaker") implanted in the left subclavian area. In order to stimulate the electrodes, the pacemaker generates rectangular electrical pulses. Typical DBS parameter settings for movement disorders range from 2 to $4 \mathrm{~V}$ amplitude, with a $60-450 \mu$ s pulse width at a frequency of $130-185 \mathrm{~Hz} .{ }^{29}$ The implantation procedure marks the first stage of the therapy; followed by the device programming process. Until recently, this was performed by painstakingly adjusting the parameters of the stimulation by trial and error. Newer techniques facilitate the programming process ${ }^{30}$ by enabling the more optimal adjustment of parameters based on:

(1) determining the precise location of the electrodes by Magnetic Resonance Imaging (MRI) or pre-operative MRI in combination with post-operative tomography imaging;

(2) determining the desired target of stimulation with the help of previous clinical experience and estimation of current spread within the brain tissue.

This approach is referred to as "open loop" DBS (OL-DBS), and although it is currently the most common technique, it has been recognized as problematic for various reasons. First, it results in a mismatch between the time course of the disease and the timing of adjustments, since clinicians can only adjust the stimulation parameters during medical appointments with patients. Second, it is based on a subjective assessment of the parameters that are beneficial in each treatment. Third, it applies a stimulus pattern established during the programming process throughout the entire lifetime of the device. This operating mode typically results in the battery discharging within $2-5$ years; ${ }^{31}$ it must then be surgically replaced, which has additional costs, stress, and risks associated with the procedure. ${ }^{32}$ Finally, the constant activity of OL-DBS can lead to undesirable permanent changes in neurotransmission in the long run, ${ }^{33}$ as well as non-stimulationdependent neural reorganization. ${ }^{34}$

To resolve these problems, researchers have investigated and developed a new generation of DBS systems, commonly referred to as "closed loop" DBS (CL-DBS). The CL-DBS paradigm is defined by the dynamic adjustment of parameters based on

\footnotetext{
${ }^{26}$ Lozano, Lipsman, Bergman et al. (2019).

27 Medtronic (2021).

28 Chhatbar, Saha (2015).

29 Kuncel, Grill (2004).

${ }^{30}$ Frankemolle, Wu, Noecker et al. (2010).

31 Ondo, Meilak, Vuong (2007).

${ }^{32}$ Deuschl, Herzog, Kleiner-Fisman et al. (2006).

33 Glannon (2016).

${ }^{34}$ Ruge, Cif, Limousin et al. (2011).
} 
the patient's current clinical condition assessed by measuring brain activity. ${ }^{35} \mathrm{CL}-\mathrm{DBS}$ developed from the field of brain-computer interfaces (BCIs) - algorithms intended to identify the intentions of a person from brain activity to provide control over prosthetic/ assistive devices. ${ }^{36}$ Implementing BCIs in CL-DBS systems allows classification of brain activity as "healthy" or "adverse." 37 Thanks to this procedure, CL-DBS can deliver and adjust stimulation in real time according to the particular needs of the patient. For example, when employed in the treatment of epilepsy, it detects early indicators of seizures and applies current to prevent the impending attacks. ${ }^{38}$ Compared to OL-DBS, CL-DBS systems result in better adaptation to specific disease dynamics, less invasiveness in neurotransmission, and reduced battery consumption. ${ }^{39}$ The CL-DBS paradigm has shown promising results for both neurological diseases like epilepsy ${ }^{40}$ or PD, ${ }^{41}$ as well as psychiatric disorders such as OCD and major depression. ${ }^{42}$

The emerging trend in DBS-based treatments is not only meant to facilitate the automatic adjustment of the stimulation in response to the abnormal neuronal activation associated with a given disease, but also to provide patients with the kind of active control which allows them to respond to the symptoms and autonomously address therapeutic goals. Systems that aim to facilitate this differ operationally from CL-DBS systems, as they are closed-loop advisory brain devices ${ }^{43}$ or volitional CL-DBS (VCL-DBS) ${ }^{44}$ In short, when the device detects unwanted neuronal activation, it gives a patient a visual or auditory signal. On this basis, the patient can decide whether stimulation should begin, be increased, and/or rejected. ${ }^{45}$ Hence, VCL-DBS enables the patients to stay "in the decisional therapeutic loop" ${ }^{46}$ In that regard, it offers them additional opportunities to choose between experiencing symptoms and suffering side effects. However, it produces other risks which will be considered in the following sections.

\section{Reports of DBS-induced changes to the self of patients}

As mentioned above, DBS is a last resort treatment for intractable diseases and it often provides beneficial therapeutic effects. Therefore, patients suffering from such diseases who are not candidates for DBS or do not have access to it will continue to suffer from untreated symptoms of their disorder. But DBS itself can also lead to unwanted side effects. Thus, there are adverse effects which may sometimes constitute inevitable tradeoffs for DBS when it is used to control disease-related symptoms. Therefore, one of the crucial questions in the neuroethics of DBS is how we should evaluate the comparative

${ }^{35}$ Miocinovic, Somayajula, Chitnis et al. (2013).

${ }^{36}$ Widge, Dougherty, Moritz (2014).

${ }^{37}$ That is, responsible for the symptoms of a given ailment.

${ }^{38}$ Morrell (2011).

39 Parastarfeizabadi, Kouzani (2017).

40 Cook, O'Brien, Berkovic et al. (2013).

${ }^{41}$ Little, Pogosyan, Neal et al. (2013).

${ }^{42}$ Aggarwal, Chugh (2020).

${ }^{43}$ Gilbert, O'Brien, Cook (2018).

${ }_{44}$ Brown, Moore, Herron et al. (2016).

${ }^{45}$ Goering, Klein, Dougherty et al. (2017).

${ }^{46}$ Gilbert, O'Brien, Cook (2018). 
risks and benefits of taking DBS therapy (as well as not receiving it at all). Two main lines of risk analysis associated with DBS have appeared in the neuroethical literature: (more) traditional and non-traditional. The former, more traditional forms of threats resulting from DBS therapy include effects in several domains: physical, ${ }^{47}{ }^{4}$ ognitive ${ }^{48}$ affective, ${ }^{49}$ and communication disorders. ${ }^{50}$ Moreover, DBS may also lead to unrealistic expectations for treatment, ${ }^{51}$ suicidal ideation, ${ }^{52}$ issues associated with informed consent, ${ }^{53}$ privacy and data security, ${ }^{54}$ and have regulatory implications. ${ }^{55}$

DBS also appears to constitute threats that have not traditionally been discussed in the literature concerning the implications of neurotechnologies. ${ }^{56}$ They have become the subject of lively interest in recent years, when many neuroethicists have expressed concerns over the potential negative impact of DBS on the selves of patients. ${ }^{57}$ These concerns were initially raised by individual reports of patients treated with DBS.

One such example was the case of a man suffering from Tourette's syndrome. As soon as the amplitude of DBS increased, he rolled into the corner, covered his face, and repeated in a high, broken voice that he was innocent. The sentences he spoke were grammatically incorrect. When the medical staff tried to help him, he would not allow it, and kept shouting that he was afraid of being locked in the basement. However, when the amplitude of the stimulation was reduced, the patient returned to his previous self, forgetting what had happened, and only reporting that he had a dim recollection of being overwhelmed by bad memories from his childhood..$^{58}$

There have also been cases of patients who, despite functioning seemingly well in most of their everyday activities, nonetheless experienced extreme personality changes and developed uncharacteristic behavior. For example, Bhargava and Doshi reported the cases of a 70-year-old male and a 58-year-old female suffering from advanced PD, who underwent subthalamic nucleus stimulation to treat the motor symptoms of PD. ${ }^{59} \mathrm{How}-$ ever, DBS induced sexual urges in these patients; urges they were unable to control. At the one-month follow-up visit, the wife of the 70-year-old man reported to the doctors that after DBS "he would insist on sexual gratification every night and would become very aggressive if denied. Once satisfied he would return back to his normal self." ${ }^{60} \mathrm{Sim}-$

${ }_{47}$ Chan, Zhu, Yeung et al. (2009).

${ }^{48}$ Witt, Daniels, Reiff et al. (2008).

${ }^{49}$ Rabins, Appleby, Brandt et al. (2009).

${ }^{50}$ Ahlberg, Laakso, Hartelius (2011).

${ }^{51}$ Montel, Bungener (2009).

${ }^{52}$ Gilbert (2013).

${ }^{53}$ Beeker, Schlaepfer, Coenen (2017); Glannon (2010); Nyholm, Campbell (2016).

${ }^{54}$ Denning, Matsuoka, Kohno (2009).

55 Stahl, Cabrera, Gibb (2018).

${ }^{56}$ More recently, the potential of another neurotechnology, i.e., the memory-modifying potential of optogenetics, has prompted neuroethicists to discuss non-traditional risks also in the context of possible future use of optogenetics (see: Adamczyk, Zawadzki, 2020; Zawadzki, Adamczyk, 2021).

57 Baylis (2013); Clausen (2009); Gilbert (2018); Glannon (2014b); Hildt (2006); Merkel, Boer, Fegert et al. (2007); Nyholm, O’Neill (2016); Schechtman (2010); Schermer (2011); Synofzik, Schlaepfer (2008); Witt, Kuhn, Timmermann et al. (2013).

${ }^{58}$ Goethals, Jacobs, Van der Linden et al. (2008).

${ }^{59}$ Bhargava, Doshi (2008).

${ }^{60}$ Ibidem. 
ilarly, the 58-year-old woman preoperatively had almost no sexual relationship with her husband for years, but after DBS she often forced herself into her husband's room for sexual purposes. More strikingly, with time she also started to expose herself to other males in her family, demanding sex. Surprisingly, despite experiencing these changes, whenever doctors evaluated her, she acted as " an extremely mature person who showed no indications of her abnormal behavior." 61 This behavior continued for five years, until it was controlled with the introduction of an antipsychotic drug.

Another example of DBS-induced changes to the self of a person is the case of a patient suffering from OCD, known in the literature under the cryptonym "Mr. B." His treatment with DBS was effective, but simultaneously caused an unexpected reaction. Under the influence of DBS therapy, Mr. B. became a fan of a very narrow subset of music: Johnny Cash's songs from the late stage of his career, that is, when the musician's voice became "harsher." His new appreciation was so intense that he bought all of the performer's records and assigned selected works to specific occasions and moods. Moreover, he claimed that listening to Cash's music gave him confidence. When the device was turned off, however, Mr. B. lost interest in the artist's music, along with his newly acquired self-confidence. Mr. B. applied two separate names for his self-transformations: "Mr B. I" to the self when DBS was turned off, and "Mr. B. II" to the self with the activated device. He also behaved in a way that made the medical staff believe that whenever DBS was active, he felt like a new, improved version of himself. ${ }^{62}$

Lipsman and Glannon, inspired by an actual clinical case, ${ }^{63}$ proposed an example of a 70-year-old professor suffering from PD, who, unlike Mr. B, did not feel that DBS treatment had radical self-transformative effects, but his relatives reported that it was the case. Along with a reduction in symptoms of the disease, the patient acquired a tendency to impulsiveness and mood swings, involving rapid changes from a depressed to a euphoric state. Due to these changes, his daughter reported that she no longer perceived her father to be the same person than before the therapy: "It's as if he's someone else entirely, [...] he's there, and he's our dad, but not like we've always known him." 64

More reports of cases in which patients experienced similar changes due to DBS treatment can be found in various qualitative studies, ${ }^{65}$ as well as the first systematic study addressing these unwanted effects in a semiquantitative way which has been

\footnotetext{
${ }^{61}$ Ibidem.

${ }^{62}$ Mantione, Figee, Denys (2014).

${ }^{63}$ Some details of the actual case that inspired Lipsman and Glannon's vignette was changed to preserve confidentiality and to emphasize some aspects of the case that the authors wanted to highlight. Thus, it is important to emphasize that although cases discussed by Lipsman and Glannon are not "uncommon" in the current DBS practice, there are fictional components in this particular vignette in contrast to the all previously discussed cases.

${ }^{64}$ Lipsman, Glannon (2013).

${ }^{65}$ Agid, Schüpbach, Gargiulo et al. (2006); de Haan, Rietveld, Stokhof et al. (2013); de Haan, Rietveld, Stokhof et al. (2015); Gilbert, Goddard, Viaña et al. (2017); Gilbert, Viaña (2018); Gilbert (2018); Haahr, Kirkevold, Hall et al. (2013); Hariz, Limousin, Tisch et al. (2011); Houeto (2002); Lewis, Maier, Horstkötter et al. (2015); Liddle, Phillips, Gustafsson et al. (2018); Mathers, Rick, Jenkinson et al. (2016); Pham, Solbakk, Skogseid et al. (2015); Scaratti, Zorzi, Guastafierro et al. (2020); Schüpbach, Gargiulo, Welter et al. (2006); Smeets, Duits, Horstkötter et al. (2018); Thomson, Segrave, Carter (2019); Thomson, Segrave, Racine et al. (2020).
} 
recently published. ${ }^{66}$ Based on these results, there is now a broad consensus in the neuroethical literature that DBS may fundamentally alter the selves of patients. ${ }^{67}$ However, how a neuroethicist captures DBS-induced changes depends on a conceptual scheme she applies. Over the years, scholars have proposed various different understandings of the self, this elusive, yet familiar phenomenon.

\section{Theories of the self and neuroethical considerations of DBS}

One of the first theories of the self proposed in the neuroethical literature ${ }^{68}$ in an attempt to understand DBS effects was that of Synofzik and Schlaepfer. ${ }^{69}$ In opposition to the subjective tradition of theories of the self, such as the Cartesian concept, they propose a naturalistic model, describing the self as an objective, biological-cognitive representative system with the ability of self-representation. This self-representation, however, is not built by a homogeneous, monolithic entity. In contrast to how it phenomenally appears, the self is in fact constructed by various modules operating on different levels of representational and functional complexity. The most fundamental are levels consisting of sensomotor processes, while the most complex are those covering conceptual and meta-representational processes. This system of self-representation is able to produce subjective representations of the self of a person based on her actions, perceptions, emotions, and beliefs. Witt et al. criticize Synofzik and Schlaepfer's model ${ }^{70}$ they point out that if one was to consistently maintain it, the self would become an ephemeral, ever-changing phenomenon. As such, this approach is not helpful for understanding the actual clinical cases of patients that experienced DBS-induced changes.

Witt and colleagues propose a foundational-function model, in which only changes in central attitudes of the person, i.e., beliefs, expectations, desires, ideals, or plans, could pose a real threat to the self. From this hierarchical perspective, only DBS-induced changes in the most central attitudes imply self-disruption. In order to apply this theory to neuroethical considerations, one must identify which attitudes count as "core" or "central" for a person. Moreover, one should also ask why changes in core attitudes should matter from a moral perspective, as well as how one could distinguish between changes that matter morally from those that do not. The authors offer some guidance for the future empirical research that might allow clarification of these issues. ${ }^{71}$

In contrast to both of the theories described above, Schechtman argues that the self should be understood in narrative terms. ${ }^{72}$ She claims that only narrative identity,

${ }^{66}$ Eich, Müller, Schulze-Bonhage (2019).

${ }^{67}$ Though there are important exceptions; for example, the literature review of Gilbert, Viaña, Ineichen (2018) who examined over 1,500 articles to investigate the scientific evidence regarding DBS-induced changes on the personality, and suggest that the theoretical neuroethics debate on the putative effects of DBS relies on limited empirical evidence.

${ }^{68}$ In reconstructing the debate on the nature of the self in the neuroethical literature, I build on the article of Dings and de Bruin (2016), in which the authors identified the most influential theoretical positions proposed in this discussion.

${ }^{69}$ Synofzik, Schlaepfer (2008).

${ }^{70}$ Witt, Kuhn, Timmermann et al. (2013).

${ }^{71}$ Ibidem.

${ }^{72}$ Schechtman (2009); Schechtman (2010). 
with its historical dimension allowing the introduction of patterns of coherence and meaning between individual experiences, meets a commonsensical expectation for our concept of the self. We create who we are through the construction of an autobiographical narrative. The relation of the narrative and the self can be conceptualized in two ways in this approach: narrative can play a strong role (i.e., create the self), or a weak role (i.e., be created by the self). However, we are probably dealing here with something similar to the hermeneutic circle, i.e., the self of the person is constructed by the narrative. On the other hand, this narrative is narrated by that person's self. ${ }^{73}$ Not all narratives can be identified as constituting the self. ${ }^{74}$ For this to be the case, they must meet the constraints of articulation and reality. The first constraint states that a person must be able to present her story, life situation and motivations. It does not have to be an accurate and completely coherent story, but the narrator should be able to explain why she does what she does, believes what she believes, and feels what she feels. The second constraint indicates that the personal narrative must be coherent with the basic facts about the person and her life. The narrative cannot be delusional, rest on evident factual errors, be resistant to revision in light of contrary evidence, or be entirely inconsistent with how others view ourselves. ${ }^{75}$ Baylis considers Schechtman's claim regarding the narrative and autobiographical nature of the self to be true. ${ }^{76}$ However, she embraces an account of the self inspired by feminist thought, in which the self is constituted in and through relationships. In her relational approach, Baylis recognizes embodied nature of the self that is situated in particular social, cultural, political, and historical contexts. She claims that the self resides not only in the brain, but in the negotiated spaces between one's body and brain as well as the brains and bodies of others. In Baylis's approach, the narrative constitutive for the self effectively balances between how the person perceives and understands herself, and how others perceive and understand her. In this model, the potentially threatening effects of DBS on the selves of patients are those that can disturb this balance in a way that would infringe on the person's autonomy.

\section{Problems of proposed models of the self and some suggestions for their resolution}

It seems that the disagreement in the literature regarding the concept that adequately characterizes the self in the context of the neuroethical considerations concerning the consequences of DBS is profound. Furthermore, most approaches postulate relatively narrow concepts of the self, focusing on one or two of its aspects, and emphasize the representational, ${ }^{77}$ functional, ${ }^{78}$ narrative, ${ }^{79}$ or relational dimensions. ${ }^{80,81}$ As Dings and de Bruin note, the narrow scope of the proposed models of the self is problematic, as

\footnotetext{
73 Trzópek (2013): 232.

74 Schechtman (1990): 113-114.

75 Schechtman (1996): 119-128.

76 Baylis (2012); Baylis (2013).

77 Synofzik, Schlaepfer (2008).

78 Witt, Daniels, Reiff et al. (2008).

79 Schechtman (2009); Schechtman (2010).

80 Baylis (2012); Baylis (2013).

81 There is also important affordance-based account of de Haan, Rietveld, Stokhof et al. (2013) focusing on enactive dimension.
} 
most of them aim to provide a complete understanding of the potential consequences of DBS on the self. ${ }^{82}$ Finally, the influential theories described above discuss DBS-induced changes in general, which renders it difficult to use them to account for changes specific to the disease treated with DBS, as well as changes specific to the type of DBS system utilized in a given therapy (i.e. OL-DBS, CL-DBS, or VCL-DBS).

This theoretical pluralism, combined with the lack of consensus regarding an adequate understanding of the concept of the self, has become a particularly pressing issue in recent years in the context of the ongoing neuroethical debate. These circumstances preclude the provision of a consensual explanation of the effects of DBS on the selves of patients, and consequently, prevent the development of a uniform procedure for evaluating the implications of DBS in individual clinical cases. In turn, this makes it impossible to calculate the benefits and risks related to decisions to initiate, continue, or discontinue the treatment.

At the same time, however, there can be a tendency in the neuroethical literature to regard considerations on the effects of DBS exclusively through the lens of a specific model of the self as an approach that is too coarse-grained. Realizing that theoretical disputes regarding the most adequate model of the self are far from reaching a resolution, neuroethicists have engaged in more fine-grained considerations of the effects of DBS on the selves of patients. For instance, some applied the concept of burden of normality to explain postoperative experiences of DBS patients. According to this notion, DBS patients may experience difficulties in adjusting to becoming "normal," ${ }^{83}$ meaning that they cannot cope with the fact of being symptom-free. ${ }^{84}$ Although the notion of burden of normality is central in explaining some of the difficulties experienced by successfully "treated" DBS patients, the majority of the discussion of DBS postoperative changes to the self is focused on abnormal side effects. As the extensive literature review undertaken in this article reflects, neuroethicists employ various concepts related to the notion of the self in this debate such as personal identity, ${ }^{85}$ authenticity, ${ }^{86}$ and autonomy. ${ }^{87}$ The engagement of researchers and the constantly growing number of theoretical works analyzing the effects of DBS in terms of the concepts mentioned above show that these concepts are regarded as crucial to understanding a broader scope of DBS threats to the selves of patients. Thus, this paper attempts to present the most relevant potential consequences of DBS in these crucial "dimensions" of the self.

\footnotetext{
${ }^{82}$ Dings, de Bruin (2016).

${ }^{83}$ Many thanks to the anonymous reviewer for pointing out that this important notion of the neuroethics of DBS is worth mentioning in this context.

${ }^{84}$ Baertschi, Favez, Radomska et al. (2019); Gilbert (2012).

${ }^{85}$ Baylis (2013); Bluhm, Cabrera, McKenzie (2019); Focquaert, DeRidder (2009); Lipsman, Glannon (2013); Mathews (2011); Schechtman (2010); Witt, Kuhn, Timmermann et al. (2013).

${ }^{86}$ Gisquet (2008); Johansson, Garwicz, Kanje et al. (2011); Johansson, Garwicz, Kanje et al. (2014); Kraemer (2013a); Kraemer (2013b); Mackenzie, Walker (2015); Mackenzie (2014); Maslen, Pugh, Savulescu (2015); Mosley, Hall, Forlini et al. (2014); Nyholm, O’Neill (2016); Pugh, Maslen, Savulescu (2017a); Pugh, Maslen, Savulescu (2017b).

${ }^{87}$ Brown, Thompson, Herron et al. (2016); Clausen (2010); Douglas (2014); Gilbert (2015); Gilbert, O'Brien, Cook (2018); Glannon (2014a); Goddard (2017); Goering (2015); Goering, Klein, Dougherty et al. (2017); Kellmeyer, Cochrane, Müller et al. (2016); Klein (2015); Müller, Walter (2010); Pugh, Pycroft, Sandberg et al. (2018); Unterrainer, Oduncu (2015); Wardrope (2014).
} 


\section{Personal identity and DBS}

In Gilbert's study, 8 out of 17 patients (47\%) reported changes in self-perception after DBS. Some seemed to experience alterations to their sense of the self. ${ }^{88}$ For example, Patient 4 said: "I feel like I am who I am now. But it's not the me that went into the surgery [...] No I can't be the real me anymore - I can't pretend. [...] Well, I think that I felt that the person that I have been was somehow observing somebody else but it wasn't me." Patient 7 reported: “Oh God, I wasn't me and I knew I wasn't me and there was nothing I could do about it [...] I knew what it was! I knew it had been turned up that day. Unlike the drugs which creep up on you and you don't know what's happening. With this, I knew what it was so I knew it was fixable." Patient 13 revealed: "I would revert to a state of hysterics or something like that much more easily than I would normally have done [...] I felt like I had lost my true self, it was way behind me." Others reported changes in activities, mood, or socio-familial dynamics; for example, Patient 14 recounted: "I lost all interest in painting." When interviewer asked: "Would you say that it was voluntary or involuntary loss of interest?," the subject replied, "Involuntary. I tried sitting down and paint something, but I just didn't want to do it." Schüpbach reported that among 29 patients with PD (15 male, 14 female) examined during a 3-year study, 66\% expressed feeling of strangeness and unfamiliarity with themselves after DBS. ${ }^{89}$ For example, Patient 1, a 38-year-old female journalist, married with one child, reported "Now I feel like a machine, I've lost my passion. I don't recognize myself anymore." Other patients in this study reported: "I don't feel like myself anymore," or "I haven't found myself again after the operation."

Schechtman's narrative model of self, ${ }^{90}$ in which narratives constitute the self if they meet articulation and reality constraints, has been most influential in the analyses of such cases..$^{91}$ If a person cannot construct a narrative fulfilling these conditions, or given dispositions, thoughts, or actions are recognized as resulting from DBS's action, not from the individual's plans, desires, or needs that are part of the narrative of the self, the personal identity of the patient is threatened. However, when considering the influence of DBS on the patients' identities within the narrative account, Schechtman concludes that, although DBS can lead to disruption of personal narrative, the narrative approach itself suggests "a way to bring potential discontinuities back into one's life narrative, rather than allowing them to disrupt it." 92 In her narrative account, a person might reconstruct and reconstitute her identity in the face of randomness and temporal change, as well as contingencies, such as illness, accidents, traumas, or neurointerventions, by incorporating them into her self-understanding and life story. As the narrative is a dynamic concept, preservation of personal identity could be compatible even if the changes that the patients experience are substantial. Schechtman provides an example

\footnotetext{
88 Gilbert (2018).

89 Schüpbach, Gargiulo, Welter et al. (2006).

90 Other versions of narrative concepts of personal identity can be found, for example, in the works of Ricoeur (1991), Mackenzie, Poltera (2010), or Atkins (2008).

91 Schechtman (1996); Schechtman (2009); Schechtman (2010).

92 Schechtman (2010).
} 
of the resolution of this sort by recalling the case of an initially alienated woman studied by Schüpbach et al., who managed to cope with the fact that she had an electronic device in her brain by creating an artwork depicting her chest X-ray with the stimulator. Schechtman interprets this case as an example of a patient precluding the threat of DBS to her identity by engaging in constructing and maintaining a coherent narrative of change, and as a result, managing to post-operatively "find herself again" ${ }^{93}$

Narrative concepts are one of the most frequently used models of the self in the contemporary neuroethical debate around DBS; however, the ideas behind these concepts suffer from various problems. Mackenzie and Walker ${ }^{94}$ point out the following weaknesses of the narrative approach: narratives accounts suggest more authorial control over people's lives and identities than they in fact have; ${ }^{95}$ imply that we must constantly self-consciously reflect on them; ${ }^{96}$ and involve interpretation rather than representation of our life stories, which raises the question of how one could distinguish truthful from confabulated ones. ${ }^{97}$ Because advocates of narrative accounts have already responded to these critiques, ${ }^{98}$ here, I focus on important arguments for why narrative accounts of personal identity are questionable, coming from recent research on the psychology of memory and reflections on cases of patients with neurological disorders.

Patients suffering from episodic amnesia whose episodic memory ${ }^{99}$ system has been disrupted or damaged seem to retain access to facts about their selves; that is, if a system of semantic ${ }^{100}$ self-knowledge of one's own traits ${ }^{101}$ remains intact, it can potentially form the foundation for a sense of personal identity. In fact, some researchers have reached similar conclusions in recent years. ${ }^{102}$ This result suggests that narrative approaches do not adequately capture conditions for the sense of identity, since, due to the non-functional episodic memory system, a person not only cannot create a narrative that meets the articulation and reality constraints imposed by Schechtman, but may not

\footnotetext{
${ }^{93}$ Ibidem.

${ }^{94}$ Mackenzie, Walker (2015).

${ }^{95}$ Christman (2004).

${ }^{96}$ Strawson (2004).

${ }_{97}$ Matthews, Kennett (2012).

${ }_{98}$ Mackenzie, Walker (2015).
}

${ }^{99}$ Episodic memory system records events as being experienced by the self from a specific point of view in time and space. Remembrance of these events takes place by re-experiencing them in a quasiperceptual way, i.e., with the awareness that "this happened to me" (see: Tulving, 1985; Tulving, 1993; Wheeler, Stuss, Tulving 1997).

${ }^{100}$ Semantic memory contains relatively general, contextless knowledge (e.g., apples are round). It usually "lacks memory" of the source of its origin, i.e., it is experienced as knowledge without reference to circumstances of where and when it was acquired. Semantic memory system may also contain knowledge about facts related to the self (e.g., I was born in Warsaw). However, one does not have to reproduce the context of acquiring this knowledge in order to retrieve information, even when the knowledge regards the very self of a person.

${ }^{101}$ Knowledge of one's own traits is a kind of semantic self-knowledge system (see: Tulving, 1985; Tulving, 1993; Wheeler, Stuss, Tulving, 1997). It has a form of generalizations and summaries of one's dispositions. These generalized summaries are a form of database that allows decision-making processes to quickly evaluate one's characteristics (see, e.g., Klein, Gangi, 2010; Klein, Cosmides, Costabile et al., 2002).

102 See: Craver (2012); Haslam, Jetten, Haslam et al. (2011); Illman, Rathbone, Kemp et al. (2011); Klein (2013). 
be able to create any narrative at all about her life. ${ }^{103}$ Nevertheless, a person still retains relevant sense of the self. Such a conclusion seems to hold in several clinical cases of various neurological disorders. ${ }^{104}$ Obviously, the issue of the empirical adequacy of narrative models, as well as a potential falsification of the narrative as the necessary condition for personal identity, require further detailed discussion which is beyond the scope of this paper. ${ }^{105}$

However, there are also issues associated with narrative theories that are more apparent and pressing in the context of neuroethical considerations. Narrative theories can be undermined not only from the position that they do not adequately show the foundation upon which the sense (or experience) of personal identity stands (necessary condition), but also from the argument that they do not give justice to the multidimensionality of the analyzed entity, namely, the self. This is because narrative theories fall into the category of "deflationary" conceptions of the self - they claim that the self is one thing and nothing more. ${ }^{106}$ This, in turn, does not allow for a sufficiently rich account of the self in the framework in which one could understand all relevant threats that DBS may pose to personal identity.

Two issues require resolution in this context. First, neuroethical considerations should make use of a theory of the self that finds the features of the self that are necessary to preserve personal identity. Second, this theory should embrace more aspects of the self. ${ }^{107}$ Responding to these concerns would help in constructing an account of personal identity which is capable of explaining the diachronic constitution and reconstitution of the identities of DBS patients.

\section{Authenticity and DBS}

In recent neuroethical literature, the concept of authenticity has become increasingly influential in addressing the threats to the self posed by DBS. For some, ${ }^{108}$ authenticity is in strict interrelation with narrative identity; if the desires of a person would have been fundamentally altered by DBS in a manner that does not fit within her narrative identity, then these desires are not authentically owned by this person. Others argue that: "The appeal to authenticity is redundant and blurs the distinction between narrative identity and autonomy." 109

The most basic idea of authenticity was well expressed by William: "Some things are in some real sense really you, or express what you are, and others aren't." 110 Such a characterization implies that humans have various elements of the self; some of these

\footnotetext{
${ }^{103}$ A disorder known as dysnarrativia.

104 See, e.g., Klein (2014); Klein (2012); Klein (2013); Klein, Nichols (2012); Klein, Lax (2010).

${ }^{105}$ For example, there is a need for a conceptual discussion on the notions associated with personal identity, such as, sense of personal identity, self-continuity, sense of the self, as well as the issue of how they relate to one another.

106 Gallagher (2018).

107 For such a multidimensional proposition see: e.g. Dings, de Bruin (2016); Gallagher (2018); Zawadzki (2020).

${ }^{108}$ For example, Christman (2009); Sharp, Wasserman (2016).

109 Mackenzie, Walker (2015).

110 As cited in Johansson, Garwicz, Kanje et al. (2011).
} 
elements are parts of the true selves, and others are not. In this approach, being authentic assumes we are living in accordance with elements that are part of our true selves, and alienated from those that are not. Kraemer claims that appealing to the concepts of "authenticity" and "alienation" in explaining the experience of patients after DBS could allow us to better understand these patients, and, in some cases, could even lead to the re-evaluation of the consequences of DBS for the self. ${ }^{111}$

In the context of DBS treatment, Kraemer interprets reports like "I feel like myself" as expressions of authenticity. Alienation, on the other hand, as the opposition to authenticity, is indicated by the following statements: "I felt like I had lost my true self, it was way behind me.", ${ }^{112}$ or "I don't feel like myself anymore." 113 Kraemer regards both authenticity and alienation as mental states. In her view, they are not neutral experiences, however; they involve normative component: authenticity is something that a person should strive for, alienation is something one should avoid. She believes that this normative component stems from the way we experience these states. Counterintuitively, however, authenticity does not necessarily have to be a pleasant experience for the person. Feeling authentic can be difficult, yet valuable. Similarly, alienation, despite being something one ought to avoid, may be experienced positively. Kraemer cites Frederick Neuhouser in explaining what alienation can "mean" for the person experiencing it: "a sense of meaninglessness or estrangement, a loss of power in relation to self and world, and a subjugation to the products of one's own activity." Both of these experiences seem to be present in patients receiving DBS treatment.

For example, in the case of Patient 1 in Schüpbach et al. mentioned above, researchers reported that she had been a dynamic person before DBS despite her motor handicap. ${ }^{114}$ However, after 18 months of treatment, despite a major improvement of her motor symptoms due to STN stimulation, she reported that she no longer felt like herself; she was no longer able to conduct any professional activity, constantly felt exhausted, and had lost her vitality, interest in her family, inspiration, and taste for life in general. Kraemer claims that the experiences of this patient can be explained when considered alongside the concept of alienation: "After treatment, not only does her work-life seem alienating, but also she feels alienated from life-goals she identified with, as well as from her new, improved body."115

However, DBS can also have the opposite effect on the self; namely, patients may feel that the treatment allows them to find their true selves. Kraemer analyzed the case of Patient 2 from the study of Schüpbach et al., a 48-year-old male accountant who worked part-time for 7 years because of PD. Before DBS, he required daily care, with his wife helping him with all of his daily tasks. After receiving treatment, he felt empowered and decided to regain control over his life. He reported "During all these years I was asleep, now I am going to take my life in hand, my life before PD." Kraemer interprets this case as reintroducing the connection of the patient with his own true self. She suggests that

\footnotetext{
111 Kraemer (2013b).

112 Gilbert (2018).

113 Schüpbach, Gargiulo, Welter et al. (2006).

114 Ibidem.

115 Kraemer (2013b).
} 
the claim about "taking life in his own hands" indicates that, before DBS, the patient felt that he was inauthentic, and alienated from his true self; the treatment, however, made him ready to become the "master of his own destiny," with the means to live a life aligned with his true self.

Kraemer postulates that both Patient 1 and Patient 2 seem to distinguish two modes in their lives: "mode one," that is, the mode experienced when they regard themselves as authentic; and "mode two," the mode they experience when alienated from their true selves. For Patient 2, the "authentic mode" was realized when under treatment; then, he felt ready to reclaim his real life ("I want to regain my life, my life before PD"). For him, PD was the cause of being in "mode two". He felt that his illness put his true self to sleep; he felt that his life was not really his own during PD, and thus he reported being alienated. Strikingly, the experiences of Patient 1 are in contradiction with those of Patient 2. Patient 1 had felt that her "mode one" was present when she was diseased. Her daily struggle with PD gave her goal in life. She reports: "Before stimulation, I wanted to be like everybody else, I didn't want to be considered only as sick. I fought for that every day! Now I find myself less impassioned, I regret the period where I did battle. Now it's the warrior's repose, I no longer have something to struggle against, my life is empty. I get up every day, but have no goal, no horizon."

Kraemer notes that Patient 2 identifies authenticity with autonomy. For him, in order to become himself, he must regain autonomous functioning by freeing himself from the care of his wife. It is worth pointing out that the case of Patient 1 also shows the crucial role of autonomy in experiencing authenticity. Her constant struggle with her disease gave Patient 1 purpose; its realization gave her a sense of agency, ${ }^{116}$ which she could not find after the successful treatment. ${ }^{117}$ Both of these interpretations are consistent in that prominent philosophical accounts of autonomy take authenticity as partially constitutive of autonomy. ${ }^{118}$ For example, Christman explicitly states "Put most simply, to be autonomous is to be one's own person, to be directed by considerations, desires, conditions, and characteristics that are not simply imposed externally upon one, but are part of what can somehow be considered one's authentic self." ${ }^{119}$ For this reason, in the following sections I focus on the latter of those dimensions potentially endangered by the effects of DBS-autonomy.

\section{Autonomy and various DBS systems}

The reference point in the neuroethical literature concerning the possible effects of DBS on autonomy is a hierarchical model proposed by Frankfurt. ${ }^{120}$ Frankfurt argues that autonomy requires a person's ability to possess second-order volitions with which she identifies - that is, regards them as authentic elements of herself. Crucially, second-or-

\footnotetext{
${ }^{116}$ For a systematic approach to the role of such narrative factors in the sense of agency, see: Zawadzki (2021).

${ }^{117}$ It is worth noting that this case can also be interpreted as an example of the "burden of normality".

118 Wardrope (2014).

${ }^{119}$ Christman (2018).

${ }^{120}$ Frankfurt (1969); Frankfurt (1971).
} 
der volitions also enable a person to distance herself from spontaneous, often elusive, first-order desires. In this view, autonomy emerges when there is a congruency between a person's second-order volitions and her first-order desires; an autonomous person endorses her first-order desires. In contrast, autonomy is disrupted when there is a discrepancy between second-order volitions and first-order desires, but the person still behaves in accordance with the dictates of the latter.

One example, where Frankfurt's model of autonomy has been applied from the ethical point of view of DBS treatments concerns patients with anorexia nervosa. Müller et al. suggest that people suffering from anorexia become caught in a vicious circle from which they cannot escape: they want to starve themselves despite knowing that such behavior is unhealthy and threatens their lives. ${ }^{121}$ Interpreting this scheme against the background of Frankfurt's theory of autonomy, the first-order desires dominate over the second-order volitions of these patients.

Maslen, Pugh, and Savulescu discuss the potential of DBS as a means to treat the symptoms of anorexia. ${ }^{122}$ They debate various strategies to achieve this goal; one, inspired by Frankfurt's theory, is termed "promotion of comparative cognitive control." There are two ways in which comparative cognitive control can be enhanced with DBS: either by reducing the compulsive need to diet and avoid eating, or by increasing top-down control over this compulsion. If the patient experiences an irresistible first-order desire that does not align with her autonomously chosen goals, reducing the strength of such a compulsive urge with the use of DBS can help the patient to regain control and act in a manner aligned with her higher-order desires. Conversely, in cases in which the patient feels that the motivation to engage in weight loss behaviors expresses her authentic self, she may not welcome an attempt to reduce her first-order desire that leads to a positively valued end. However, Maslen, Pugh, and Savulescu claim that, even in such situations, DBS could still promote the person's autonomy even if it only serves as a means to give her resources to be more successful in self-governing by remedying a failure in top-down cortical control over compulsive drives to diet. Maslen and colleagues compare this strategy to the situation of a person, who can resist drinking, but nonetheless chooses to drink on some occasions. This strategy, however, seems riskier than the former, as it assumes that the person will choose (due to the additional cognitive resources) to behave in a manner aligned with other second-order desires, like desire to survive, sufficiently often.

Frankfurt's autonomy model can help examine the ethics of DBS treatment, and it even illuminates the therapeutic potential of DBS in cases of patients suffering from certain diseases, such as anorexia. However, the future of the ethics of DBS will require a theory of autonomy that takes into account not only challenges related to the specific ailments DBS aims to treat, but also the new kinds of threats arising from the technology of DBS itself - that is, emerging forms of treatments, like advisory brain devices ${ }^{123}$ or VCL-DBS. ${ }^{124}$ It might seem that patients' autonomy will only be enhanced by these

121 Müller, Riedmüller, Walter et al. (2015).

122 Maslen, Pugh, Savulescu (2015).

${ }^{123}$ Gilbert, O'Brien, Cook (2018).

124 Brown, Moore, Herron et al. (2016). 
technologies, as patients play a decisive role in applying stimulation with such systems. While some authors argue that this is the case, others claim that such a result is far from obvious. Below, these issues are analyzed in the context of widely debated case of "the Dutch Patient" (DP); I discuss it in a different context than it is usually the case in neuroethical literature. Most authors consider the ethics of this case from the perspective of taking the most adequate measures to respect DP's autonomy in his complex institutional situation. Below, the hypothetical situation in which DP uses one of the emerging forms of DBS treatments is presented as an illustration of a potential threat to his autonomy that could arise solely from the technology used.

DP was treated for PD with the help of OL-DBS. The treatment was effective, but it caused multiple side effects: mania, megalomania, and impulsiveness. Given that the treatment appeared to be leading the patient to compulsive gambling, falling into debt, conflict with the police, and ultimately, forced hospitalization in a psychiatric hospital, doctors faced a dilemma about whether the device should be permanently disabled. The solution that seemed appropriate to the medical staff was to temporarily turn off the device and then ask the patient about his preferences concerning the continuation of DBS therapy. With his DBS disabled, DP decided that it was more important to him to stop the symptoms of PD, even given the symptoms caused by DBS, and signed an advance directive agreeing to remain under psychiatric care while the device was activated. ${ }^{125}$

There is much to consider from the ethical point of view of DP. For example, whether DP's behavior under DBS was the result of realizing authentic desires of his true self; whether it was autonomous,; ${ }^{126}$ and even whether DP was autonomous when the device was turned off, or if DBS irreversibly changed him. ${ }^{127}$ Here, however, as mentioned above, even more complicated hypothetical scenario building upon the case of DP, in which is assumed to have used a DBS system of the new generation, will be considered.

New DBS systems allow patients to stay in "the decisional loop." However, there is no data concerning the impact of such systems on the sense of self of the patients. Recently, Gilbert, O'Brien, and Cook addressed this gap by examining how the first-in-humans experimental advisory brain devices capable of predicting epilepsy seizures influence the sense of autonomy of patients. ${ }^{128}$ To this end, researchers conducted in-depth semi structured interviews to obtain first-person narratives of the subjective experiences of patients. Gilbert and colleagues regrouped subjects into five phenomenological clusters reflecting patients' autonomy and decision-making processes: (1) insecurities and risks attached to living with epilepsy; (2) how patients integrate device predictions into their deliberative processes leading up to their relevant decisions; (3) patients' distrust of the device; (4) device-induced sense of control and empowerment; and (5) device-induced lack of confidence and sense of control. The authors' analysis of the data led them to the following conclusions: 1) being in the loop may partly increase a sense of autonomy over decision-making; 2) being in the loop may partly decrease a

\footnotetext{
125 Smeding (2008).

126 Kraemer (2013a).

127 For a discussion of the reversibility of DBS see: Pugh (2019).

128 Gilbert, O'Brien, Cook (2018).
} 
sense of autonomy over decision-making; 3) being in the loop may not impact a sense of autonomy over decision-making.

Here, I would like to focus on one seemingly paradoxical consequence of Conclusion 1, namely that increasing a sense of autonomy over decision-making by staying in the decisional loop can actually lead to a decrease in a patient's overall autonomy. Klein et al., discussing the ethics of VCL-DBS in the context of psychiatric disorders, raises this issue by indicating that there is a possibility that "if a patient is given control over device settings, the temptation to increase stimulation settings to feel better and better may be difficult to resist, and patients may fear the introduction of a new kind of addiction." 129 It is worth noting here that VCL-DBS systems may not only threaten patient autonomy when used to treat addiction; it seems to be an inherent risk of the use of DBS systems that give control to the patients (regardless of the disorder being treated).

Even in the case of PD patients, such as DP, there is a threat to autonomy if the patient is treated with the use of a VCL-DBS system. If experiencing DBS-related euphoria, a common symptom in the manic state, DP could experience an insurmountable temptation to turn on and amplify the stimulation, in order to achieve this phenomenologically pleasant mental state. As he would have total control over the device, he could enter a self-destructive cycle, leading him to engage in riskier, or even dangerous actions. As Brown, Moore, et al. point out in discussing the case of DP: "Mania is often accompanied by feelings of grandiosity or invulnerability, and so a patient may refuse to acknowledge the negative consequences of their stimulation." 130 They further comment that for this reason, DP's autonomy could be "hijacked" or could become "addicted" to the system through a feedback loop that causes him to decide to leave the device constantly turned on. In this type of case, what is particularly problematic is that, if medical staff working with OL-DBS could easily detect dangerous changes in behavior at the time of programming, with VCL-DBS, patients could potentially trigger and experience changes over time, in a manner that preclude early detection and re-programming of the device. Moreover, patients "addicted" from achieving a desired psychological state may even intentionally hide dangerous symptoms caused by the stimulation by turning it off during medical appointments.

Interestingly, Pugh et al. argue that one may still understand $\mathrm{DP}^{\prime}$ s choice as enhancing his autonomy, if the stimulation allows him to achieve the goals that he himself believes that he has most reasons to achieve. ${ }^{131}$ They quote Unterrainer and Oduncu in using the notion of Ulysses' contract to analyze the case of DP in this context. ${ }^{132}$ Just as Ulysses tied himself to the mast as a means to protect himself from being lured to his death by the Sirens' song, so DP had to reduce his autonomy to achieve his desired end; DP chose to live in a state of mania, in order to avoid remaining bed-ridden due to his motor disability. Pugh and colleagues argue that this means DP's decision can be interpreted as actually enhancing autonomy. His actions facilitated the pursuit of the desired end he felt was most important for him, even if the effects of his decision took away his freedom to achieve other competing goals.

${ }^{129}$ Klein, Goering, Gagne et al. (2016).

130 Brown, Moore, Herron et al. (2016).

${ }^{131}$ Pugh, Pycroft, Sandberg et al. (2018).

${ }^{132}$ Unterrainer, Oduncu (2015). 
While this perspective may seem convincing in the particular case of DP, it can be ethically problematic as a general rule; DP's decision not only takes away his liberty in pursuing competing goals, but also undermines his autonomy in regard to all possible decisions afterwards. Although making decision with the DBS device disabled allowed him to exercise autonomy in a given moment in time, it led him to sacrifice his autonomy in the future. One could understand this dilemma better as the choice between local and global autonomy. ${ }^{133}$ In a local understanding of autonomy, one may ask whether a person is autonomous with regard to a particular decision in a given situation at a given time, and whether she has the necessary resources to act in a manner aligned with her will. In a global sense of autonomy, on the other hand, one may ask whether a person is able to autonomously pursue chosen goals over an extended period. From this perspective, one could argue that DP enhanced his local autonomy at the cost of reducing, or in his extreme case, erasing his global autonomy (as DBS diminished DP's autonomy both in terms of permanent volitional impairments, e.g., compulsive gambling and mania, and the physical restriction of his freedom in the form of compulsory lifelong hospitalization). Although local autonomy, the autonomy of a particular decision, is relevant, there are situations in which we should give it up in order to make paternalistic decisions to preserve the global autonomy of the patient. This is particularly important if this kind of decision has severe life-altering consequences. DP's case could seemingly serve as an example of such an approach; however, in his case, the relevant choice is not only between different kinds of autonomy, but also between global autonomy and movement abilities required for normal everyday functioning.

Taking into account the fact that DBS is a last resort therapy, patients such as DP have failed to respond to all other treatments and thus it is imperative to emphasize that DP would continue to suffer from untreated symptoms of the disease without DBS. It therefore seems that DP has to face a dramatic choice between prisons of different sizes and types - in the case of being treated, a ward and a "mental prison," and if left untreated, a bed. This makes DP's choice almost impossible to assess from a neuroethical standpoint $t^{134}$ and devastating for the patient and his family. At this point, we should also note that PD that could make DP bedridden poses a threat not only to his autonomy, but also to his identity and authenticity. Thus, symptoms of the disease that DBS can control are as much of a threat to these dimensions of the self as the adverse side effects of the treatment. It should therefore be emphasized once again that there is no choice between DBS and the "neutral state" of the patient. The choice concerning taking DBS therapy is always entangled in a situational context in which the patient has a very serious and intractable disease. To conclude, the case of DP is extremely complicated from the neuroethical perspective because it is profoundly difficult to assess whether the symptoms of the disease or the institutional and psychiatric side effects of treating it should be considered more beneficial (or harmful). Moreover, it is impossible to simply transfer the responsibility for the decision to the patient himself (which might seem the best option in such a difficult situation) because it is not obvious at which moment the patient is ac-

${ }_{133}$ Dworkin (1988).

${ }^{134}$ After all, what is worse - the symptoms of the disease or the institutional and psychiatric side effects of treating it? 
tually given an autonomous choice (whether it is when his local (synchronous) or global (diachronic) autonomy is respected). As discussed above, both DP's decision-making process as well as his final decision depend on what kind of autonomy decision-makers (i.e., legal guardians, clinicians, ethical boards) choose to respect.

The utilization of OL-DBS in the actual case of DP led him to be considered non-autonomous, and effectively prompted the medical staff to temporarily turn off the device. Only under this condition did doctors ask him about his preferences concerning further therapy. In this decision, the local autonomy of the patient was the most important factor. The utilization of a VCL-DBS system could further complicate cases such as $\mathrm{DP}^{\prime} \mathrm{s}$, as its use can be intertwined with a sense of autonomy and self-narrative of the patient. Unlike OL-DBS systems, where there seems to be clarity concerning the forces distinct from the self which influence the behavior of a person, in VCL-DBS, a patient may experience the sense of agency stemming from the control over the stimulation. This could lead the patient to feel more responsible for his actions during treatment, as he might not attribute the changes in his behavior to the external force of DBS, but rather to his own weakness of will that prevented him from turning off the stimulation.

Such considerations lead to the conclusion that OL-DBS and VCL-DBS systems can have both positive and negative consequences for the autonomy of patients. The influence of each of these types of DBS, however, differs in substantial ways. Being in the decisional loop can further complicate the impact of DBS on patient autonomy, instead of straightforwardly enhancing it. Moreover, local (or synchronous) autonomy is not necessarily the same as the global (or diachronic) autonomy of the patient. Finally, discussion of the case of DP indicates one more relationship that must be addressed regarding the ethics of DBS; namely, that autonomy of a person is interwoven with her own sense of responsibility. However, as there is currently a gap in the knowledge concerning how remaining in the decisional loop influences patients' sense of responsibility, and there is only one theoretical work concerning hypothetical cases that has sought to prepare the stage for conceptual considerations regarding this issue ${ }^{135}$ more work in neuroethics will be required to understand this complex relationship.

\section{Conclusions}

The article examined potential threats posed by various DBS treatments to the selves of patients and various dimensions related to these threats: personal identity, authenticity, and autonomy. The most influential theoretical models and practical considerations explored in the neuroethical literature have been critically analyzed in this paper. I argued that various proposed models may be theoretically, empirically, or ethically questionable, and thus their further refinement seems to be required.

I have pointed out why narrative models of personal identity seem to be empirically questionable, and why their deflationary character poses a problem for accounting for DBS threats to the identities of patients. Focusing on different aspects of DBS threats to the self, I applied concepts of authenticity and alienation to better understand patients' reports after DBS. The analysis of clinical cases undertaken here suggests that the issue of

135 Brown, Moore, Herron et al. (2016). 
authenticity is interwoven with the issue of autonomy of the patient. Frankfurt's account of autonomy, with its embedded authenticity reference, proved helpful in examining the ethics of DBS treatment, as well as in illuminating therapeutic potential of DBS in cases of patients with anorexia. However, as pointed out, modern DBS systems (e.g., VCL-DBS) require a theory of autonomy that can account for new kinds of threats arising from technological innovation in DBS treatments. In particular, the issue of "being inside the decisional loop" was analyzed against the background context of various related theories. I have adopted the notions of local (synchronous) and global (diachronic) autonomy to account for the potential consequences of utilizing such systems in DBS therapies, and concluded that these two concepts may sometimes be at odds with each other. Finally, I have pointed out the relationship between autonomy and the sense of responsibility in DBS patients and indicated the need for neuroethicists to further study this relationship.

This paper sought to demonstrate that the effects of DBS on the selves of patients cannot be accounted for solely through the lens of any specific extant model of the self; more fine-grained concepts are required. The extensive review of the literature undertaken in this article shows that neuroethicists should employ notions of personal identity, authenticity, and autonomy in the ongoing debate, as DBS poses tangible threats to the selves of patients in these dimensions. The considerations described and examined in this paper show that these dimensions are intertwined, and that DBS's potential impact on the selves of patients can only be properly understood when all of these factors are taken into account. Hence, novel approaches that carefully scrutinize the complex interrelations between these dimensions are needed to gain new insights into the ethics of neuromodulatory treatments such as DBS.

\section{Funding}

Research work was financed by the Polish Ministry of Science and Higher Education from the budget for science in 2017-2021 under the "Diamond Grant" program (Diamond Grant no. 0188/DIA/2017/46).

\section{References}

Adamczyk A.K., Zawadzki P. (2020), “The Memory-Modifying Potential of Optogenetics and the Need for Neuroethics," NanoEthics 14 (3): 207-225.

Aggarwal S., Chugh N. (2020), “Ethical Implications of Closed Loop Brain Device: 10-Year Review," Minds and Machines 30 (1): 145-170.

Agid Y., Schüpbach M., Gargiulo M. et al. (2006), “Neurosurgery in Parkinson's Disease: The Doctor Is Happy, the Patient Less So?," Journal of Neural Transmission. Supplementum 70: 409-414.

Ahlberg E., Laakso K., Hartelius L. (2011), "Perceived Changes in Communication as an Effect of STN Surgery in Parkinson's Disease: A Qualitative Interview Study," Parkinson's Disease 2011: 1-9.

Atkins K. (2008), Narrative Identity and Moral Identity: A Practical Perspective, Routledge, New York. 
Baertschi M., Favez N., Radomska M. et al. (2019), “An Empirical Study on the Application of the Burden of Normality to Patients Undergoing Deep Brain Stimulation for Parkinson's Disease," Journal of Psychosocial Rehabilitation and Mental Health 6 (2): 175-186.

Baylis F. (2012), “The Self in Situ: A Relational Account of Personal Identity," [in:] Being Relational: Reflections on Relational Theory and Health Law, J. Downie, J.J. Llewelyn (eds.), BC: UBC Press, Vancouver: 109-131.

Baylis F. (2013), “'I Am Who I Am': On the Perceived Threats to Personal Identity from Deep Brain Stimulation," Neuroethics 6 (3): 513-526.

Beeker T., Schlaepfer T.E., Coenen V.A. (2017), “Autonomy in Depressive Patients Undergoing DBS-Treatment: Informed Consent, Freedom of Will and DBS' Potential to Restore It," Frontiers in Integrative Neuroscience 11: 1-11.

Beszłej J., Siwicki D., Fila-Witecka K. et al. (2019), “Deep Brain Stimulation in ObsessiveCompulsive Disorder - case report of two patients," Psychiatria Polska 53 (4): 807-824.

Beszłej J., Wieczorek T., Kobyłko A. et al. (2019), “Deep Brain Stimulation: New Possibilities for the Treatment of Mental Disorders," Psychiatria Polska 53 (4): 789-806.

Bewernick B.H., Kayser S., Sturm V. et al. (2012), “Long-Term Effects of Nucleus Accumbens Deep Brain Stimulation in Treatment-Resistant Depression: Evidence for Sustained Efficacy," Neuropsychopharmacology: Official Publication of the American College of Neuropsychopharmacology 37 (9): 1975-1985.

Bhargava P., Doshi P. (2008), "Hypersexuality Following Subthalamic Nucleus Stimulation for Parkinson's Disease," Neurology India 56 (4): 474-476.

Bluhm R., Cabrera L., McKenzie R. (2019), "What We (Should) Talk about When We Talk about Deep Brain Stimulation and Personal Identity," Neuroethics 13 (3): 289-301.

Brown T., Moore P., Herron J. et al. (2016), "Personal Responsibility in the Age of UserControlled Neuroprosthetics," [in:] 2016 IEEE International Symposium on Ethics in Engineering, Science and Technology (ETHICS), BC: IEEE, Vancouver: 1-12.

Brown T., Thompson M.C., Herron J. et al. (2016), “Controlling Our Brains - a Case Study on the Implications of Brain-Computer Interface-Triggered Deep Brain Stimulation for Essential Tremor," Brain-Computer Interfaces 3 (4): 165-170.

Chan D.T.M., Zhu X.L., Yeung J.H.M. et al. (2009), “Complications of Deep Brain Stimulation: A Collective Review," Asian Journal of Surgery 32 (4): 258-263.

Chhatbar P.Y., Saha S. (2015), “Ethical Considerations of Neuroprostheses," [in:] Implantable Neuroprostheses for Restoring Function, K. Kilgore (ed.), Woodhead Publishing Series in Biomaterials: 413-428.

Chiken S., Nambu A. (2015), “Mechanism of Deep Brain Stimulation: Inhibition, Excitation, or Disruption?," The Neuroscientist 22 (3): 313-322.

Christman J. (2004), “Narrative Unity as a Condition of Personhood," Metaphilosophy 35 (5): 695-713.

Christman J. (2009), The Politics of Persons: Individual Autonomy and Socio-Historical Selves, Cambridge University Press, Cambridge.

Christman J. (2018), "Autonomy in Moral and Political Philosophy," [in:] The Stanford Encyclopedia of Philosophy, E.N. Zalta (ed.), Spring 2018, Metaphysics Research Lab, Stanford University, URL = https:/ / plato.stanford.edu/archives/spr2018/entries/ autonomy-moral/ [Accessed 21.03.2020].

Clausen J. (2009), “Man, Machine and in Between,” Nature 457 (7233): 1080-1081.

Clausen J. (2010), "Ethical Brain Stimulation - Neuroethics of Deep Brain Stimulation in Research and Clinical Practice," European Journal of Neuroscience 32 (7): 1152-1162. 
Cook M.J., O'Brien T.J., Berkovic S.F. et al. (2013), “Prediction of Seizure Likelihood with a Long-Term, Implanted Seizure Advisory System in Patients with Drug-Resistant Epilepsy: A First-in-Man Study," The Lancet Neurology 12 (6): 563-571.

Corripio I., Roldán A., Sarró S. et al. (2020), “Deep Brain Stimulation in Treatment Resistant Schizophrenia: A Pilot Randomized Cross-over Clinical Trial," EBioMedicine 51: 102568.

Craver C.F. (2012), “A Preliminary Case for Amnesic Selves: Toward a Clinical Moral Psychology," Social Cognition 30 (4): 449-473.

Denning T., Matsuoka Y., Kohno T. (2009), “Neurosecurity: Security and Privacy for Neural Devices," Neurosurgical Focus 27 (1): E7.

Deuschl G., Herzog J., Kleiner-Fisman G. et al. (2006), “Deep Brain Stimulation: Postoperative Issues," Movement Disorders: Official Journal of the Movement Disorder Society 21 (14): 219-237.

Dings R., de Bruin L. (2016), "Situating the Self: Understanding the Effects of Deep Brain Stimulation," Phenomenology and the Cognitive Sciences 15 (2): 151-165.

Douglas T. (2014), "Criminal Rehabilitation Through Medical Intervention: Moral Liability and the Right to Bodily Integrity," The Journal of Ethics 18 (2): 101-122.

Dworkin G. (1988), The Theory and Practice of Autonomy, Cambridge University Press, Cambridge.

Eich S., Müller O., Schulze-Bonhage A. (2019), “Changes in Self-Perception in Patients Treated with Neurostimulating Devices," Epilepsy \& Behavior 90: 25-30.

Falowski S.M. (2015), “Deep Brain Stimulation for Chronic Pain,” Current Pain and Headache Reports 19 (7): 27.

Fisher R., Salanova V., Witt T. et al., SANTE Study Group (2010), "Electrical Stimulation of the Anterior Nucleus of Thalamus for Treatment of Refractory Epilepsy," Epilepsia 51 (5): 899-908.

Fitzgerald P.B., Segrave R.A. (2015), “Deep Brain Stimulation in Mental Health: Review of Evidence for Clinical Efficacy," Australian \& New Zealand Journal of Psychiatry 49 (11): 979-993.

Focquaert F., DeRidder D. (2009), "Direct Intervention in the Brain: Ethical Issues Concerning Personal Identity," Journal of Ethics in Mental Health 4 (2): 1-7.

Frankemolle A.M.M., Wu J., Noecker A.M. et al. (2010), “Reversing Cognitive-Motor Impairments in Parkinson's Disease Patients Using a Computational Modelling Approach to Deep Brain Stimulation Programming," Brain 133: 746-761.

Frankfurt H.G. (1969), "Alternate Possibilities and Moral Responsibility," Journal of Philosophy 66 (23): 829.

Frankfurt H.G. (1971), "Freedom of the Will and the Concept of a Person," The Journal of Philosophy 68 (1): 5-20.

Franzini A., Broggi G., Cordella R. et al. (2013), “Deep-Brain Stimulation for Aggressive and Disruptive Behavior," World Neurosurgery 80: S29.e11-14.

Gallagher S. (2018), "Deep Brain Stimulation, Self and Relational Autonomy," Neuroethics 18: $1-13$.

Gardner J. (2013), “A History of Deep Brain Stimulation: Technological Innovation and the Role of Clinical Assessment Tools," Social Studies of Science 43 (5): 707-728.

Gilbert F. (2012), “The Burden of Normality: From 'Chronically Ill' to 'Symptom Free'. New Ethical Challenges for Deep Brain Stimulation Postoperative Treatment," Journal of Medical Ethics 38 (7): 408-412. 
Gilbert F. (2013), “Deep Brain Stimulation and Postoperative Suicidality Among Treatment Resistant Depression Patients: Should Eligibility Protocols Exclude Patients with a History of Suicide Attempts and Anger/Impulsivity?," AJOB Neuroscience 4 (1): 28-35.

Gilbert F. (2015), "A Threat to Autonomy? The Intrusion of Predictive Brain Implants," AJOB Neuroscience 6 (4): 4-11.

Gilbert F. (2018), “Deep Brain Stimulation: Inducing Self-Estrangement,” Neuroethics 11 (2): 157-165.

Gilbert F., Goddard E., Viaña J.N.M. et al. (2017), “I Miss Being Me: Phenomenological Effects of Deep Brain Stimulation," AJOB Neuroscience 8 (2): 96-109.

Gilbert F., O'Brien T., Cook M. (2018), “The Effects of Closed-Loop Brain Implants on Autonomy and Deliberation: What Are the Risks of Being Kept in the Loop?," Cambridge Quarterly of Healthcare Ethics 27 (2): 316-325.

Gilbert F., Viaña J.N.M. (2018), “A Personal Narrative on Living and Dealing with Psychiatric Symptoms after DBS Surgery," Narrative Inquiry in Bioethics 8 (1): 67-77.

Gilbert F., Viaña J.N.M., Ineichen C. (2018), “Deflating the ‘DBS Causes Personality Changes' Bubble," Neuroethics: 1-17.

Gisquet E. (2008), “Cerebral Implants and Parkinson's Disease: A Unique Form of Biographical Disruption?," Social Science \& Medicine 67 (11): 1847-1851.

Glannon W. (2010), "Consent to Deep Brain Stimulation for Neurological and Psychiatric Disorders," The Journal of Clinical Ethics 21 (2): 104-111.

Glannon W. (2014a), “Neuromodulation, Agency and Autonomy,” Brain Topography 27 (1): 46-54.

Glannon W. (2014b), "Philosophical Reflections on Therapeutic Brain Stimulation," Frontiers in Computational Neuroscience 8 (54): 1-3.

Glannon W. (2016), "Ethical Issues in Neuroprosthetics," Journal of Neural Engineering 13 (2): 021002.

Goddard E. (2017), “Deep Brain Stimulation Through the 'Lens of Agency': Clarifying Threats to Personal Identity from Neurological Intervention," Neuroethics 10 (3): 325-335.

Goering S. (2015), "Stimulating Autonomy: DBS and the Prospect of Choosing to Control Ourselves Through Stimulation," AJOB Neuroscience 6 (4): 1-3.

Goering S., Klein E., Dougherty D.D. et al. (2017), "Staying in the Loop: Relational Agency and Identity in Next-Generation DBS for Psychiatry," AJOB Neuroscience 8 (2): 59-70.

Goethals I., Jacobs F., Van der Linden C. et al. (2008), "Brain Activation Associated with Deep Brain Stimulation Causing Dissociation in a Patient with Tourette's Syndrome," Journal of Trauma \& Dissociation 9 (4): 543-549.

Haahr A., Kirkevold M., Hall E.O.C. et al. (2013), "'Being in It Together': Living with a Partner Receiving Deep Brain Stimulation for Advanced Parkinson's Disease - a Hermeneutic Phenomenological Study," Journal of Advanced Nursing 69 (2): 338-347.

de Haan S., Rietveld E., Stokhof M. et al. (2013), "The Phenomenology of Deep Brain Stimulation-Induced Changes in OCD: An Enactive Affordance-Based Model," Frontiers in Human Neuroscience 7 (653): 1-14.

de Haan S., Rietveld E., Stokhof M. et al. (2015), “Effects of Deep Brain Stimulation on the Lived Experience of Obsessive-Compulsive Disorder Patients: In-Depth Interviews with 18 Patients," PLOS ONE 10 (8): e0135524.

Hamani C., Pilitsis J., Rughani A.I. et al. (2014), “Deep Brain Stimulation for Obsessive-Compulsive Disorder Systematic Review and Evidence-Based Guideline Sponsored by the American Society for Stereotactic and Functional Neurosurgery and the Congress of 
Neurological Surgeons (CNS) and Endorsed by the CNS and American Association of Neurological Surgeons," Neurosurgery 75 (4): 327-333.

Hariz G.-M., Limousin P., Tisch S. et al. (2011), "Patients' Perceptions of Life Shift after Deep Brain Stimulation for Primary Dystonia-A Qualitative Study," Movement Disorders 26: 2101-2106.

Haslam C., Jetten J., Haslam S.A. et al. (2011), "“I Remember Therefore I Am, and I Am Therefore I Remember': Exploring the Contributions of Episodic and Semantic Self-Knowledge to Strength of Identity," British Journal of Psychology 102 (2): 184-203.

Hemm S., Wårdell K. (2010), "Stereotactic Implantation of Deep Brain Stimulation Electrodes: A Review of Technical Systems, Methods and Emerging Tools," Medical \& Biological Engineering \& Computing 48 (7): 611-624.

Herrington T.M., Cheng J.J., Eskandar E.N. (2016), "Mechanisms of Deep Brain Stimulation," Journal of Neurophysiology 115 (1): 19-38.

Hickey P., Stacy M. (2016), “Deep Brain Stimulation: A Paradigm Shifting Approach to Treat Parkinson's Disease," Frontiers in Neuroscience 10 (173): 1-11.

Hildt E. (2006), "Electrodes in the Brain: Some Anthropological and Ethical Aspects of Deep Brain Stimulation," International Review of Information Ethics 5 (9): 33-39.

Houeto J.L. (2002), "Behavioural Disorders, Parkinson's Disease and Subthalamic Stimulation," Journal of Neurology, Neurosurgery \& Psychiatry 72 (6): 701-707.

Illman N.A., Rathbone C.J., Kemp S. (2011), "Autobiographical Memory and the Self in a Case of Transient Epileptic Amnesia," Epilepsy E Behavior 21 (1): 36-41.

Johansson V., Garwicz M., Kanje M. et al. (2014), “Thinking Ahead on Deep Brain Stimulation: An Analysis of the Ethical Implications of a Developing Technology," AJOB Neuroscience 5 (1): 24-33.

Johansson V., Garwicz M., Kanje M. et al. (2011), “Authenticity, Depression, and Deep Brain Stimulation," Frontiers in Integrative Neuroscience 5 (21): 1-3.

Karas P.J., Mikell C.B., Christian E. et al. (2013), “Deep Brain Stimulation: A Mechanistic and Clinical Update," Neurosurgical Focus 35 (5): E1.

Kellmeyer P., Cochrane T., Müller O. et al. (2016), “The Effects of Closed-Loop Medical Devices on the Autonomy and Accountability of Persons and Systems," Cambridge Quarterly of Healthcare Ethics 25 (4): 623-633.

Klein E. (2015), "Are Brain-Computer Interface (BCI) Devices a Form of Internal Coercion?," AJOB Neuroscience 6 (4): 32-34.

Klein E., Goering S., Gagne J. et al. (2016), “Brain-Computer Interface-Based Control of Closed-Loop Brain Stimulation: Attitudes and Ethical Considerations," Brain-Computer Interfaces 3 (3): 140-148.

Klein S.B. (2012), "The Self and Its Brain," Social Cognition 30 (4): 474-518.

Klein S.B. (2013), "The Sense of Diachronic Personal Identity," Phenomenology and the Cognitive Sciences 12 (4): 791-811.

Klein S.B. (2014), "Sameness and the Self: Philosophical and Psychological Considerations," Frontiers in Psychology 5 (29): 1-15.

Klein S.B., Cosmides L., Costabile K.A. et al. (2002), "Is There Something Special about the Self? A Neuropsychological Case Study," Journal of Research in Personality 36 (5): 490-506.

Klein S.B., Gangi C.E. (2010), "The Multiplicity of Self: Neuropsychological Evidence and Its Implications for the Self as a Construct in Psychological Research," Annals of the New York Academy of Sciences 1191: 1-15. 
Klein S.B., Lax M.L. (2010), “The Unanticipated Resilience of Trait Self-Knowledge in the Face of Neural Damage," Memory 18 (8): 918-948.

Klein S.B., Nichols S. (2012), "Memory and the Sense of Personal Identity," Mind 121 (483): 677-702.

Kraemer F. (2013a), “Authenticity or Autonomy? When Deep Brain Stimulation Causes a Dilemma," Journal of Medical Ethics 39 (12): 757-760.

Kraemer F. (2013b), “Me, Myself and My Brain Implant: Deep Brain Stimulation Raises Questions of Personal Authenticity and Alienation," Neuroethics 6 (3): 483-497.

Kuhn J., Bührle C.P., Lenartz D. et al. (2013), “Deep Brain Stimulation in Addiction Due to Psychoactive Substance Use," Handbook of Clinical Neurology 116: 259-269.

Kuncel A.M., Grill W.M. (2004), "Selection of Stimulus Parameters for Deep Brain Stimulation," Clinical Neurophysiology 115 (11): 2431-2441.

Laxton A.W., Lozano A.M. (2013), “Deep Brain Stimulation for the Treatment of Alzheimer Disease and Dementias," World Neurosurgery 80 (3-4): S28.e1-8.

Lewis C.J., Maier F., Horstkötter N. et al. (2015), “Subjectively Perceived Personality and Mood Changes Associated with Subthalamic Stimulation in Patients with Parkinson's Disease," Psychological Medicine 45 (1): 73-85.

Liddle J., Phillips J., Gustafsson L. et al. (2018), “Understanding the Lived Experiences of Parkinson's Disease and Deep Brain Stimulation (DBS) through Occupational Changes," Australian Occupational Therapy Journal 65 (1): 45-53.

Lipsman N., Glannon W. (2013), "Brain, Mind and Machine: What Are the Implications of Deep Brain Stimulation for Perceptions of Personal Identity, Agency and Free Will?," Bioethics 27 (9): 465-470.

Lipsman N., Woodside B., Lozano A.M. (2013), "Evaluating the Potential of Deep Brain Stimulation for Treatment-Resistant Anorexia Nervosa," Handbook of Clinical Neurology 116: 271-276.

Little S., Pogosyan A., Neal S. et al. (2013), “Adaptive Deep Brain Stimulation in Advanced Parkinson Disease: Adaptive DBS in PD," Annals of Neurology 74 (3): 449-457.

Lozano A.M., Lipsman N., Bergman H. et al. (2019), “Deep Brain Stimulation: Current Challenges and Future Directions," Nature Reviews Neurology 15 (3): 148-160.

Mackenzie C., Poltera J. (2010), "Narrative Integration, Fragmented Selves, and Autonomy," Hypatia 25 (1): 31-54.

Mackenzie C., Walker M. (2015), “Neurotechnologies, Personal Identity and the Ethics of Authenticity" [in:] Handbook of Neuroethics, J. Clausen, N. Levy (eds.), Springer, Dordrecht: 373-392.

Mackenzie R. (2014), "Authenticity Versus Autonomy in Choosing the New Me: Beyond IEC and NIEC in DBS," AJOB Neuroscience 5 (1): 51-53.

Mantione M., Figee M., Denys D. (2014), “A Case of Musical Preference for Johnny Cash Following Deep Brain Stimulation of the Nucleus Accumbens," Frontiers in Behavioral Neuroscience 8 (152): 1-4.

Maslen H., Pugh J., Savulescu J. (2015), “The Ethics of Deep Brain Stimulation for the Treatment of Anorexia Nervosa," Neuroethics 8 (3): 215-230.

Mathers J., Rick C., Jenkinson C. et al. (2016), "Patients' Experiences of Deep Brain Stimulation for Parkinson's Disease: A Qualitative Systematic Review and Synthesis," BMJ Open 6 (6): e011525.

Mathews D.J.H. (2011), “Deep Brain Stimulation, Personal Identity and Policy," International Review of Psychiatry 23 (5): 486-492. 
Matthews S., Kennett J. (2012), "Truth, Lies, and the Narrative Self," American Philosophical Quarterly 49 (4): 301-315.

Medtronic (2021), "FDA Approves First-Of-Its-Kind Percept ${ }^{\mathrm{TM}}$ PC Neurostimulator with BrainSense $^{\mathrm{TM}}$ Technology," URL = https://newsroom.medtronic.com/news-releases/news-release-details/fda-approves-first-its-kind-percepttm-pc-neurostimulator [Accessed 27.03.2020].

Merkel R., Boer G., Fegert J. et al. (2007), Intervening in the Brain: Changing Psyche and Society, Springer Science \& Business Media, New York.

Miocinovic S., Somayajula S., Chitnis S. et al. (2013), “History, Applications, and Mechanisms of Deep Brain Stimulation," JAMA Neurology 70 (2): 163-171.

Montel S.R., Bungener C. (2009), "Coping and Quality of Life of Patients with Parkinson Disease Who Have Undergone Deep Brain Stimulation of the Subthalamic Nucleus," Surgical Neurology 72 (2): 105-111.

Montgomery E.B., Gale J.T. (2008), "Mechanisms of Action of Deep Brain Stimulation (DBS)," Neuroscience E Biobehavioral Reviews 32 (3): 388-407.

Morrell M.J. (2011), "Responsive Cortical Stimulation for the Treatment of Medically Intractable Partial Epilepsy," Neurology 77 (13): 1295-1304.

Mosley P.E., Hall W., Forlini C. et al. (2014), "Alienation and Authenticity in Parkinson's Disease and Its Treatment," AJOB Neuroscience 5 (4): 54-56.

Müller S., Riedmüller R., Walter H. et al. (2015), “An Ethical Evaluation of Stereotactic Neurosurgery for Anorexia Nervosa," AJOB Neuroscience 6 (4): 50-65.

Müller S., Walter H. (2010), "Reviewing Autonomy: Implications of the Neurosciences and the Free Will Debate for the Principle of Respect for the Patient's Autonomy," Cambridge Quarterly of Healthcare Ethics 19 (2): 205-217.

Nyholm S., Campbell S.M. (2016), “When Is Deep Brain Stimulation a Medical Benefit, and What Is Required for Consent?," AJOB Neuroscience 7 (3): 150-152.

Nyholm S., O'Neill E. (2016), “Deep Brain Stimulation, Continuity over Time, and the True Self," Cambridge Quarterly of Healthcare Ethics 25 (4): 647-658.

Ondo W.G., Meilak C., Vuong K.D. (2007), "Predictors of Battery Life for the Activa Soletra 7426 Neurostimulator," Parkinsonism \& Related Disorders 13 (4): 240-242.

Ostrem J.L., Racine C.A., Glass G. et al. (2011), “Subthalamic Nucleus Deep Brain Stimulation in Primary Cervical Dystonia," Neurology 76 (10): 870-878.

Parastarfeizabadi M., Kouzani A.Z. (2017), “Advances in Closed-Loop Deep Brain Stimulation Devices," Journal of Neuroengineering and Rehabilitation 14 (1): 79.

Pham U., Solbakk A.-K., Skogseid I.-M. et al. (2015), “Personality Changes after Deep Brain Stimulation in Parkinson's Disease," Parkinson's Disease 2015: 490507.

Pugh J. (2019), “No Going Back? Reversibility and Why It Matters for Deep Brain Stimulation," Journal of Medical Ethics 45 (4): 225-230.

Pugh J., Maslen H., Savulescu J. (2017a), "The Need for Further Fine-Grained Distinctions in Discussions of Authenticity and Deep Brain Stimulation," AJOB Neuroscience 8 (3): W1-W3.

Pugh J., Maslen H., Savulescu J. (2017b), “Deep Brain Stimulation, Authenticity and Value," Cambridge Quarterly of Healthcare Ethics 26 (4): 640-657.

Pugh J., Pycroft L., Sandberg A. et al. (2018), “Brainjacking in Deep Brain Stimulation and Autonomy," Ethics and Information Technology 20 (3): 219-232.

Rabins P., Appleby B.S., Brandt J. et al. (2009), "Scientific and Ethical Issues Related to Deep Brain Stimulation for Disorders of Mood, Behavior and Thought," Archives of General Psychiatry 66 (9): 931-937. 
Ricoeur, P. (1991), "Narrative Identity," Philosophy Today 35 (1): 73-81.

Ruge D., Cif L., Limousin P. et al. (2011), “Shaping Reversibility? Long-Term Deep Brain Stimulation in Dystonia: The Relationship between Effects on Electrophysiology and Clinical Symptoms," Brain: A Journal of Neurology 134 (7): 2106-2115.

Scaratti C., Zorzi G., Guastafierro E. et al. (2020), "Long Term Perceptions of Illness and Self after Deep Brain Stimulation in Pediatric Dystonia: A Narrative Research," European Journal of Paediatric Neurology 26: 61-67.

Schechtman M. (1990), "Personhood and Personal Identity," The Journal of Philosophy 87 (2): 71-92.

Schechtman M. (1996), The Constitution of Selves, Cornell University Press, Ithaca, NY.

Schechtman M. (2009), "Getting Our Stories Straight: Self-Narrative and Personal Identity," [in:] Personal Identity and Fractured Selves: Perspectives from Philosophy, Ethics, and Neuroscience, D.J.H. Mathews, H. Bok, P.V. Rabins (eds.), Johns Hopkins University Press, Baltimore: 65-92.

Schechtman M. (2010), "Philosophical Reflections on Narrative and Deep Brain Stimulation," The Journal of Clinical Ethics 21 (2): 133-139.

Schermer M. (2011), “Ethical Issues in Deep Brain Stimulation," Frontiers in Integrative Neuroscience 5 (17): 1-5.

Schiff N.D., Giacino J.T., Kalmar K. et al. (2007), “Behavioural Improvements with Thalamic Stimulation after Severe Traumatic Brain Injury," Nature 448 (7153): 600-603.

Schrock L.E., Mink J.W., Woods D.W. et al., Tourette Syndrome Association International Deep Brain Stimulation (DBS) Database and Registry Study Group (2015), “Tourette Syndrome Deep Brain Stimulation: A Review and Updated Recommendations: Tourette Syndrome DBS Guidelines," Movement Disorders 30 (4): 448-471.

Schüpbach M., Gargiulo M., Welter M.L. et al. (2006), “Neurosurgery in Parkinson Disease: A Distressed Mind in a Repaired Body?," Neurology 66 (12): 1811-1816.

Sharp D., Wasserman D. (2016), “Deep Brain Stimulation, Historicism, and Moral Responsibility," Neuroethics 9: 173-185.

Smeding H.M.M. (2008), "Neuropsychological Effects of Subthalamic Nucleus Stimulation in Parkinson's Disease," URL = http:/ / dare.uva.nl/document/106077 [Accessed 22.03.2020].

Smeets A.Y.J.M., Duits A.A., Horstkötter D. et al. (2018), “Ethics of Deep Brain Stimulation in Adolescent Patients with Refractory Tourette Syndrome: A Systematic Review and Two Case Discussions," Neuroethics 11 (2): 143-155.

Stahl D., Cabrera L., Gibb T. (2018), “Should DBS for Psychiatric Disorders Be Considered a Form of Psychosurgery? Ethical and Legal Considerations," Science and Engineering Ethics 24 (4): 1119-1142.

Starr P.A. (2013), “Deep Brain Stimulation for Other Tremors, Myoclonus, and Chorea," Handbook of Clinical Neurology 116: 209-215.

Strawson G. (2004), “Against Narrativity,” Ratio 17 (4): 428-452.

Synofzik M., Schlaepfer T.E. (2008), "Stimulating Personality: Ethical Criteria for Deep Brain Stimulation in Psychiatric Patients and for Enhancement Purposes," Biotechnology Journal 3 (12): 1511-1520.

Thomson C.J., Segrave R., Racine E. et al. (2020), "'He's Back so I'm Not Alone': The Impact of Deep Brain Stimulation on Personality, Self, and Relationships in Parkinson's Disease," Qualitative Health Research 30 (14): 2217-2233. 
Thomson C.J., Segrave R.A., Carter A. (2019), “Changes in Personality Associated with Deep Brain Stimulation: A Qualitative Evaluation of Clinician Perspectives," Neuroethics: 1-10.

Trzópek J. (2013), Na tropach podmiotu: między filozoficznym a empirycznym ujęciem podmiotowości, Wydawnictwo Uniwersytetu Jagiellońskiego, Kraków.

Tulving E. (1985), Elements of Episodic Memory, Oxford University Press, Oxford, New York. Tulving E. (1993), Self-Knowledge of an Amnesic Individual Is Represented Abstractly, [in:] "The Mental Representation of Trait and Autobiographical Knowledge about the Self," T.K. Srull, R.S. Wyer, Jr. (eds.), Lawrence Erlbaum Associates, Inc, Hillsdale: 147-156.

Unterrainer M., Oduncu F.S. (2015), “The Ethics of Deep Brain Stimulation (DBS)," Medicine, Health Care and Philosophy 18 (4): 475-485.

Vidailhet M., Jutras M.F., Grabli D. et al. (2013), "Deep Brain Stimulation for Dystonia," Journal of Neurology, Neurosurgery, and Psychiatry 84 (9): 1029-1042.

Vitek J.L. (2008), “Deep Brain Stimulation: How Does It Work?,” Cleveland Clinic Journal of Medicine 75 (2): 59-65.

Wardrope A. (2014), "Authenticity and Autonomy in Deep-Brain Stimulation," Journal of Medical Ethics 40 (8): 563-566.

Wheeler M.A., Stuss D.T., Tulving E. (1997), “Toward a Theory of Episodic Memory: The Frontal Lobes and Autonoetic Consciousness," Psychological Bulletin 121 (3): 331-354.

Whiting D.M., Tomycz N.D., Bailes J. et al. (2013), “Lateral Hypothalamic Area Deep Brain Stimulation for Refractory Obesity: A Pilot Study with Preliminary Data on Safety, Body Weight, and Energy Metabolism," Journal of Neurosurgery 119 (1): 56-63.

Widge A.S., Dougherty D.D., Moritz C.T. (2014), “Affective Brain-Computer Interfaces As Enabling Technology for Responsive Psychiatric Stimulation," Brain Computer Interfaces 1 (2): 126-136.

Witt K., Daniels C., Reiff J. et al. (2008), "Neuropsychological and Psychiatric Changes after Deep Brain Stimulation for Parkinson's Disease: A Randomised, Multicentre Study," The Lancet Neurology 7 (7): 605-614.

Witt K., Kuhn J., Timmermann L. et al. (2013), “Deep Brain Stimulation and the Search for Identity," Neuroethics 6 (3): 499-511.

Zawadzki P. (2020), "Pattern Theory of Self and Situating Moral Aspects: The Need to Include Authenticity, Autonomy and Responsibility in Understanding the Effects of Deep Brain Stimulation," Phenomenology and the Cognitive Sciences: 1-24.

Zawadzki P. (2021), "Mapping the Dimensions of Agency: The Narrative as Unifying Mechanism," AJOB Neuroscience 12 (2-3): 191-193.

Zawadzki P., Adamczyk A.K. (2021), "Personality and Authenticity in Light of the Memory-Modifying Potential of Optogenetics," AJOB Neuroscience 12 (1): 3-21. 